\section{Гуманитарные компетенции врача (кардиолога)}

Таратухин Е. O.

В статье раскрывается сущность работы с пациентом как социальным и психологическим субъектом, имеющим помимо соматической патологии переживание ситуации болезни. В качестве элементов отношений врач-пациент рассматриваются психосоциальные факторы риска сердечно-сосудистой (и шире - неинфекционной) патологии, а также социальное благополучие как компонент позитивного здоровья. Работа с человеком требует от врача иных компетенций, нежели работа с патологией на биологическом уровне. Возможно, настало время выделить в клинической медицине "врачей-биомедиков" и "врачей-лечебников", из которых первые не обязаны обладать гуманитарными компетенциями (не научены им). Поскольку неинфекционная патология в значительной мере имеет психосоматическую природу, а психические процессы наполнены переживанием социальной реальности, для работы с ними врач-клиницист должен обладать умениями из области наук о человеке, а шире - о культуре в целом. Это особенно важно ввиду феномена власти врача как представителя медицины и здравоохранения. Обсуждаются следующие компетенции: умения внутренней работы, ситуативного поиска и интерпретации, коммуникативная компетентность и этическая, развитие позитивного здоровья.

Российский кардиологический журнал. 2019;24(9):28-32

http://dx.doi.org/10.15829/1560-4071-2019-9-28-32
Ключевые слова: психосоциальные факторы риска, здоровье, психосоматика, неинфекционные заболевания, пациентоориентированность, психокардиология, врачебная этика, непрерывное образование.

Конфликт интересов: не заявлен.

ФГБОУ ВО Российский национальный исследовательский медицинский университет им. Н.И. Пирогова, Москва, Россия.

Таратухин Е. О. - к.м.н., доцент, магистр психологии, магистр культурологии, Master of Arts, зав. кафедрой биоэтики и международного медицинского права ЮHECKO, ORCID: 0000-0003-2925-0102.

Автор, ответственный за переписку (Corresponding author): cardio03@list.ru

ФГОС ВО - Федеральный государственный образовательный стандарт высшего образования.

Рукопись получена 03.08.2019

Рецензия получена 12.08.2019

Принята к публикации 19.08.2019

\title{
Humanitarian competencies of a doctor (cardiologist)
}

Taratukhin E. O

The article reveals the features of working with the patient as a social and psychological subject, who, in addition to somatic pathology, has an experience of the disease situation. Psychosocial risk factors for cardiovascular (and more generally non-infectious) pathology, as well as social well-being as a component of positive health, are considered as elements of a doctor-patient relationship. Work with a person requires from a doctor competency that differs from working with pathology at a biological level. Perhaps, the time has come to single out "biomedical doctors" and "medical doctors" in clinical medicine, of which the first ones are not required humanitarian competencies. Since non-infectious pathology largely includes psychosomatic features, and mental processes are filled with an experience of social reality, the clinician must have skills of human sciences to work with them. This is especially important in view of the physician's power as an ambassador of medicine and health. The following competencies are discussed: internal work skills, situational search and interpretation, communicative and ethical competence, development of positive health.

В образовательных стандартах высшего образования есть понятие общепрофессиональных и универсальных компетенций. Данный уровень компетенций объединяет знания и умения, свойственные вообще человеку с высшим образованием и врачу как специалисту, в частности.

Среди универсальных компетенций (в проекте ФГОС ВО с учётом профстандартов по специальности 31.05.01 - Врач-лечебник [1]), а также среди общекультурных, общепрофессиональных и профессиональных (в текущем ФГОС ВО 31.05.01 - Врачлечебное дело [2]) следует выделить ряд относящихся к гуманитарному знанию (табл. 1). Кроме того, при
Russian Journal of Cardiology. 2019;24(9):28-32 http://dx.doi.org/10.15829/1560-4071-2019-9-28-32

Key words: psychosocial risk factors, health, psychosomatics, non-communicable diseases, patient orientation, psychocardiology, medical ethics, continuing education.

Conflicts of Interest: nothing to declare.

N. I. Pirogov Russian National Research Medical University, Moscow, Russia.

Taratukhin E. O. ORCID: 0000-0003-2925-0102.

Received: 03.08.2019 Revision Received: 12.08.2019 Accepted: 19.08.2019

первичной специализированной аккредитации по кардиологии станция “Коммуникация” объективного структурированного клинического экзамена включает в себя ситуации “трудного" пациента" и “сообщения плохих новостей” [3].

Врач - представитель медицины. Медицина учение, частная наука, практика, культурное явление, сформировавшееся в тысячелетиях противостояния человека природе. Её задача продлевать жизнь с максимальным качеством, сохранять и достигать полного здоровья - благополучия на физическом, психическом и социальном уровнях устройства человека [4]. Человек биосоциален 


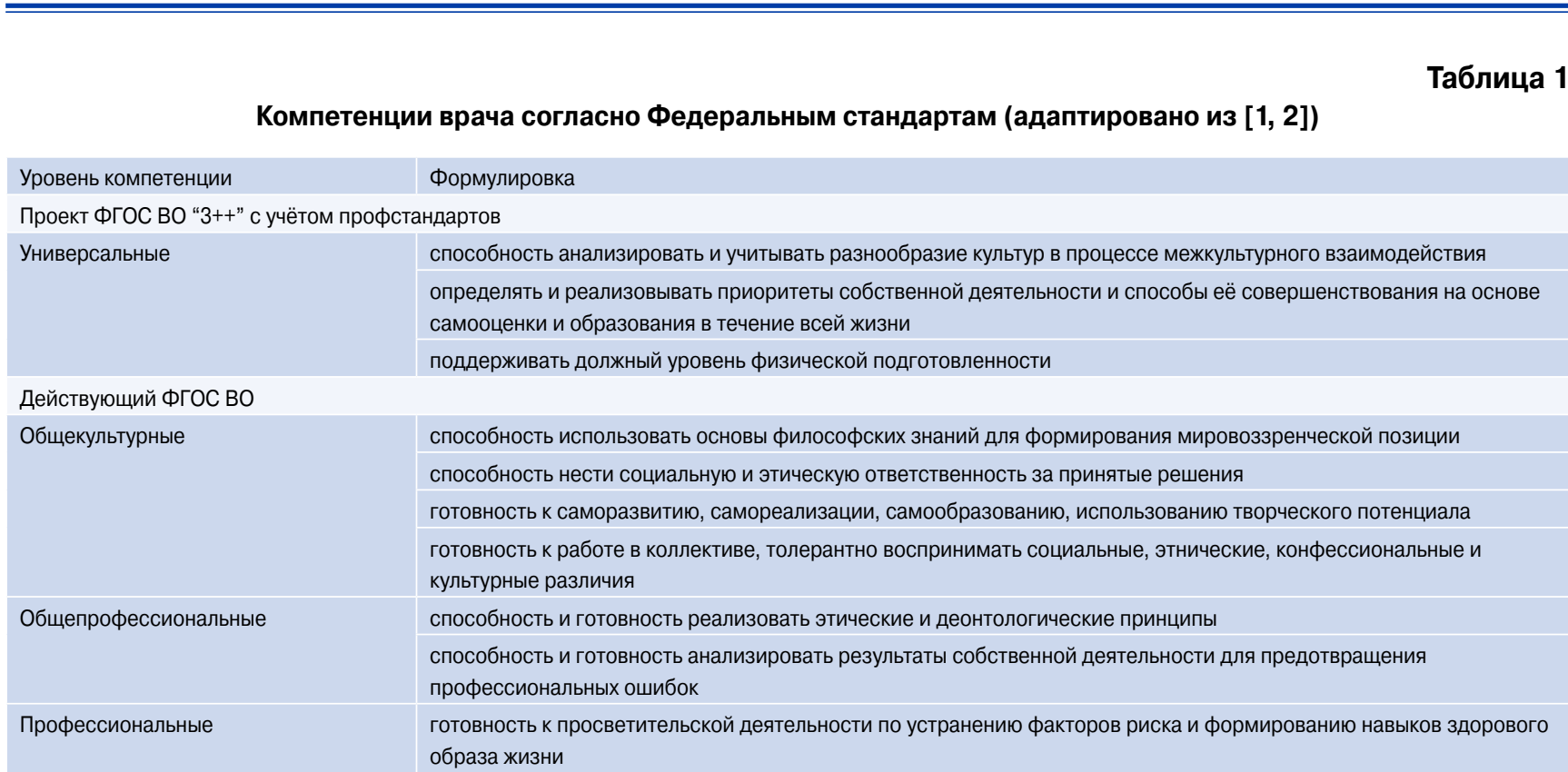

Сокращение: ФГОС ВО - Федеральный государственный образовательный стандарт высшего образования.

по своей природе. Биологическое электричество создаёт условия для мышления и коммуникации, которые реализуются в форме символов, выражаемых, воспринимаемых и интерпретируемых людьми. Так создаётся культура - вторая природа или всё, что не природа.

Работа в рамках медицины требует учёта 1) биологической стороны человека, его физиологии и патологии; 2) социальной, культурной стороны (мировоззрения, личности, контактов); 3) тесной двусторонней взаимосвязи биологического и культурного.

Биопсихосоциальная природа человека, обозначенная в определении здоровья Всемирной организации здравоохранения, может без потери смысла быть сведена к биосоциальной. Психологический уровень в данном случае (не умаляя важности психологии) есть переходный уровень, дверь между биологическими материальными процессами тела и смысловой, символической реальностью общества, т.е. коммуникации [4]. Душа, psyche или anima, есть процессы одушевления тела, психические функции: мышление, интеллект, память, эмоции, настроение и т.д. Их наполнение так или иначе символическое, коммуникативное, а реализуются они благодаря биохимическим механизмам сокращения мышц, выделения нейромедиаторов, биологического электричества.

Медицина рубежа XX-XXI веков была сугубо биологична [5]. Это легко понять, ведь стремительное развитие естественных наук затмило медленный противоречивый рост понимания человеком самого себя через философию, культурологию, социологию, психологию и искусство. Тем не менее, медицина как помощь человеку требует работы и с биологической, и с культурной его частями. В рамках клинических специальностей, вероятно, назрел момент дихотомии: или мы настойчиво развиваем у врача гуманитарные компетенции, или мы разделяем врачебную практику на два рода - предполагающую и не предполагающую наличие таких компетенций.

Консервативный путь, тот, по которому научнопедагогическое сообщество идёт сейчас, потребует обновления подходов к формированию гуманитарных компетенций у врачей (и одними из первых у кардиологов, занятых оказанием помощи при патологии с явной психосоматической природой [6]). Другой путь - осознание невозможности охватить всю комплексность биосоциальных взаимосвязей, выделение специалистов-клиницистов, способных и не способных работать с личностью человека. Возможно, это признание поражения, но возможно требование эволюции, новый, современный взгляд на медицинскую помощь. "Врач-лечебник” и "врачбиомедик”, например, названия двух типов клиницистов по способам работы с пациентом. Первый предполагает наличие коммуникативных и социальных умений на высоком уровне (достаточном, чтобы “лечить словом”), второй - лишь действия в сфере фармакологии, хирургии, методов диагностики, физиотерапии с минимальной, формальной, коммуникацией.

Консервативный путь ощущается более комфортно. Если следовать по нему, встаёт вопрос, каковы компетенции врача-клинициста, способного работать с социальным Я пациента не менее 
эффективно, чем с биологическими процессами его тела, с учётом тесной связи социального и биологического?

Взаимодействуя с больным человеком или с пациентом в рамках первичной профилактики, врач имеет дело как с “чистой” биологией, так и с символической реальностью этого человека. Введение фармакопрепарата, не говоря уже о хирургическом вмешательстве, есть не что иное, как действие на биологию пациента. Но и психологические процессы переживания (негативные и позитивные эмоции, настроение) есть биохимические состояния. Они сопряжены с осмыслением социальной жизни. Когнитивная наука исследует “воплощённое мышление” (embodied cognition) [7]. Существует множество доказательств влияния эмоций на развитие хронических заболеваний и на их обострение. Стресс - типичный пример биохимической реакции тела на осмысление социальной реальности: факторов стресса, например, изменений курса валюты, потери работы.

Биологическое реагирование хорошо изучено, оно довольно просто по своей сути. Гораздо сложнее процессы переживания - смысловые и символические процессы. Они сложны просто потому, что в отличие от биологических (естественно-научных) их для изучения невозможно генерализовать, сделать выборку и посчитать достоверность. Они сугубо индивидуальны, требуют умений интерпретации по законам гуманитарного знания. И хотя некоторые учёные-естественники не считают гуманитарное знание научным в принципе, дело не столько в обозначении его научным, сколько в его сути и практической значимости. Наука как таковая сама есть лишь один из способов познавать и менять мир [8]. Медицина же - учение более широкое, имеющее реальность жизни своим предметом, включая понятия неощущаемые (судьба, бог, душа и т.д.), но представляющие значение для больного и в итоге через переживание влияющие на его совладание с болезнью. Работая с человеком (живым, в сознании), нельзя не уметь понимать его, декодировать факторы, влияющие на его приверженность, на его отношение к ситуации болезни, на способность менять образ жизни, менять жизненный уклад в связи с медицинской ситуацией.

Отчасти исследованием человека социального занимается психология. Эта наука имеет как строгие биологические направления (нейронаука), так и социальные (консультативная психология). Гуманитарные компетенции врача - это как минимум психологические компетенции. Но для эффективной работы их недостаточно. Более того, работа с личностью происходит при помощи другой личности, а врач-клиницист не может абстрагировать свою личность от личности больного - тогда он становится “врачом-биомедиком” (см. выше). Поэтому ключевой гуманитарной компетенцией является навык и умение внутренней работы, построения осознанности, рефлексивность, конструктивная самокритика и способность меняться.

Самоидентификация человека - переживание его Я по отношению к категориям социальным. K примеру, фитнес как наращивание мышц представляет собой реализацию определённого образа телесности, который воспринимается в качестве эталона. И для одного мужчины целью окажется гипертрофия мышц как таковая, для другого достижение “греческих" пропорций и рельефа. В том и другом случае процессы происходят на уровне соматическом и человек в итоге может стать пациентом кардиолога ввиду, например, артериальной гипертензии или кардиомиопатии. Ещё более простой пример - потребление алкоголя как социальная практика. Если самоидентификация человека требует признания в определённой социальной группе, он будет вынужден потреблять избыточное количество алкоголя в ситуации застолий, тостов, классического “ты меня уважаешь? - тогда пей”. Работая с таким пациентом, мало просто запретить пагубное действие, мало даже напугать последствиями (реакция может быть обратной, например, унынием, негативизмом), нужно уметь понять его мотивацию. Мотивация исходит из ценностей, ценность обусловливается соотнесением образа своего Я с желаемым в обществе, а желаемое есть конструкт, основанный на целостном опыте человека.

Перечисленного уже достаточно для того, чтобы соматический врач сделал вывод о сложности, потенциальной бесконечности работы с человеком как личностью, социальным Я. Но не в сложности этого знания дело. Главной особенностью является качественное отличие такого знания. Оно негенерализуемо, неповторяемо, невоспроизводимо. Оно интерпретативно, а значит, требует инструментария для анализа: знаний истории и философии культуры, знаний психологии, умений коммуницировать с целью понять, а не только собрать данные. Для “врача-биомедика” боль как симптом - лишь “говорящая биология”, у которой есть некий процесс, проявляющийся жалобами на боль. Для врача-клинициста боль ещё и переживание пациента, его представления и страхи, проекция на свою жизнь, вопрос “за что?” или “всегда ли теперь так будет?”. При этом врачу совершенно не обязательно переживать боль вместе с больным; умение осознанного отношения позволяет быть вовлечённым, не переходя границы самого себя.

Важности качественной методологии в кардиологии была посвящена статья [6]. По сути, так происходит возвращение старой клинической школы 
на новом витке развития медицины. Простые отсылки к полному сбору анамнеза, к правильному разговору с больным, к учёту личностных черт будут звучать сегодня консервативно-сентиментально, если не подкреплять их современными представлениями о биосоциальных взаимосвязях, способах понимать культурную часть пациента, а самому врачу - конструировать собственную социальную идентичность.

Традиционно “небиологической части” пациента посвящены специальности и области медицины с корнем "псих-" в своём названии: психиатрия, психосоматика, психокардиология. Хотя они номинально имеют дело с процессами психологического уровня, любое проявление таких процессов состоит в ощущаемых, воспринимаемых и интерпретируемых символах. Процессы биопсихологические до тех пор недоступны, пока не обретут выражение, став психосоциальными явлениями. Уже В.А. Гиляровский говорил "каждая эпоха имеет свою психиатрию” [9]. Экстраполируя эту мысль в психокардиологию,- наполнение стрессов, вредных привычек и нездорового образа жизни как сердечно-сосудистых факторов риска лежит в окружающей информационной среде. Значит, и распутывать этиопатогенетический клубок нужно сверху. Психосоматика, психокардиология если не переопределяются, то обретают иной уровень работы. На это можно посмотреть и ещё шире, поскольку вся неинфекционная патология так или иначе начинается с психосоциальных факторов риска.

К подобной работе врача, с элементами качественной методологии, прилегает пациентоориентированность. Её наиболее простые установки требуют от медицинских работников всегда позитивного настроя, эмпатии, уважения, конструктивной коммуникации, совместного принятия решений и терпеливого, терпимого информирования.

Наконец, принятие решений в этически сложных ситуациях требует от врача являться этическим субъектом, т.е. человеком, способным понимать каждую уникальную ситуацию и находить решение в ней. Особенно, если правовая база недостаточно детализирована.

Где найти ресурс осуществлять это - и формально, и по сути? Очевидно, дело в гуманитарных компетенциях. Гуманитарный - согласно словарному определению, относящийся к обществу, человеку и его культуре (в противоположность наукам о природе). Можно обозначить следующие компетенции:

1. Внутренней работы - умение рефлексировать о своих чувствах, своём отношении к другому чело- веку (коллегам, пациентам, близким пациентов), к ситуации; находить причины своего отношения к ситуации, своих чувств, анализировать и рационализировать их; тенденция к выполнению постулата “врач, исцелись сам".

2. Ситуативного поиска и интерпретации - умение задавать вопросы о скрытых смыслах и источниках того, что происходит - как локально, в ситуации оказания помощи, так и глобально; находить коды, при помощи которых происходит представление информации, её возможное искажение, подмена.

3. Коммуникативные - умение вести диалог с пациентами, их близкими, с коллегами конструктивно, без создания ситуаций непонимания, конфликта; осознавать свои собственные переживания и порождаемые коммуникацией смыслы; выражаться нужным для эффективной коммуникации образом, учитывая феномен власти врача как представителя медицины и здравоохранения [10].

4. Этические - умение выделять этическую составляющую ситуации, различать плохое и хорошее, правильное и неправильное в ситуации; получать дополнительную информацию, необходимую для принятия этически нагруженных решений.

5. Развития позитивного здоровья - понимание устройства здоровья (благополучия) человека на социо-культурном уровне; умение интерпретировать социо-культурные детерминанты неблагополучия и находить пути их разрешения (следует добавить, что в рассмотренных стандартах и проектах стандартов образования уровней специалитета и ординатуры не обнаружены компетенции, связанные со здоровьем как междисциплинарным понятием согласно ВО3).

Развитие гуманитарных компетенций у студентов и у врачей в послевузовском и непрерывном образовании возможно при надлежащей “настройке” дисциплин гуманитарного и психологического блока. Наиболее важной является сущностная составляющая - формирование способа мыслить аналитически, использовать разные точки зрения для осмысления одного и того же явления. В современную эпоху избытка информации ключевым умением является сохранение своей самоидентификации автономной, независимой от внешних информационных влияний насколько возможно. Для врача как одного из важнейших действующих лиц в жизнях других людей это особенно актуально.

Конфликт интересов: все авторы заявляют об отсутствии потенциального конфликта интересов, требующего раскрытия в данной статье. 


\section{Литература/References}

1. Project of the Educational standard of higher education: clinical medicine. (In Russ.) Проект ФГОС ВО 3++ "Лечебное дело". http://fgosvo.ru/uploadfiles/ProjFGOSVO3++/ Spec3++/310501_C_3plus_12102017.pdf (обращение 2 августа 2019).

2. Educational standard of higher education: clinical medicine. (In Russ.) Действующий ФГОС ВО “Лечебное дело". http://fgosvo.ru/uploadfiles/fgosvospec/310501.pdf (обращение 2 августа 2019).

3. A list of Objectified structured clinical examination for Cardiology certification. (In Russ.) Перечень станций объективного структурированного клинического экзамена по специальности Кардиология при первичной специализированной аккредитации специалистов. https://fmza.ru/upload/medialibrary/e9c/perechen-stantsii_-oske_ kardiologiya_soglas_red.pdf (обращение 2 августа 2019)

4. Taratukhin EO. Risk factors hierarchy. Russ J Cardiol, 2017;9(149):28-33. (In Russ.) Таратухин Е. О. Иерархия факторов риска. Российский кардиологический журнал, 2017;9(149):28-33. doi:10.15829/1560-4071-2017-9-28-33.

5. Dreyfus HL. Medicine as combining natural and human science. $\mathrm{J}$ Med Philos. 2011;36(4):335-41. doi:10.1093/jmp/jhr027.

6. Taratukhin EO. Qualitative research in cardiology - to be virtuous or fail. Russ $\mathrm{J}$ Cardiol 2016;4(132), Engl.:195-7. (In Russ.) Таратухин Е. О. Качественные исследования в кар- диологии: виртуозно или никак. Российский кардиологический журнал. 2016:4(132), Engl.:195-7. doi:10.15829/1560-4071-2016-4-eng-195-197.

7. Shapiro L, Stolz S. Embodied cognition and its significance for education. Theory and Research in Education. 2019;17(1):19-39. doi:10.1177/1477878518822149.

8. Dobrokhotov AL. Morphology of the Culture: introduction to the problem field. In Dobrokhotov AL "Selected works", Moscow: Publishing house Territoriya budushchego, 2008, pp.7-72. (In Russ.) Доброхотов А. Л. Морфология культуры: введение в проблематику. В Доброхотов А. Л. "Избранное”, М.: Издательский дом “Территория будущего", 2008, стр.7-72.

9. Gilyarovsky VA. A study on hallucinations. Moscow, BINOM, 2003. 240p. (In Russ.) Гиляровский В. А. Учение о галлюцинациях. Москва: БИНОМ, 2003. 240 с.

10. Taratukhin EO. Patient's personality: an interdisciplinary approach to cardiovascular pathology. Russ J Cardiol. 2014;19(9):22-5. (In Russ.) Таратухин E. О. Личность больного: междисциплинарный подход в работе с кардиологической патологией. Российский кардиологический журнал. 2014;19(9):22-5. doi:10.15829/1560-40712014-9-22-25. 